\title{
Revealing Educationally Critical Aspects of Rate
}

\author{
Sandra Herbert \\ Faculty of Arts and Education \\ Deakin University \\ PO Box 423, \\ WARRNAMBOOL VIC 3280 \\ Australia \\ sandra.herbert@deakin.edu.au
}

Robyn Pierce

Melbourne Graduate School of Education

University of Melbourne VIC 3010

Australia

\section{Abstract}

\begin{abstract}
Rate (of change) is an important but complicated mathematical concept describing a ratio comparing two different numeric, measurable quantities. Research referring to students' difficulties with this concept spans more than twenty years. It suggests that problems experienced by some calculus students are likely a result of pre-existing limited or incorrect conceptions of rate. This study investigated 20 Australian Year 10 students' understanding of rate as revealed by phenomenographic analysis of interviews. Eight conceptions of rate emerged, leading to the identification of four educationally critical aspects of the concept which address gaps in students' thinking. In addition, the employment of phenomenography, to reveal conceptions of rate, is described in detail.
\end{abstract}

\section{Corresponding Author:}

Sandra Herbert

Faculty of Arts and Education

Deakin University

PO Box 423,

WARRNAMBOOL VIC 3280

Australia

Phone: 0355633068

Fax: 0355633534

Email: sandra.herbert@deakin.edu.au

\section{Key words}

Secondary school mathematics

Rate

Rate of Change

Phenomenography

Educationally critical aspects

Calculus 


\section{Introduction}

Rate (of change) is an important mathematical concept needed for everyday numeracy and important for more advanced areas of study, such as calculus. An understanding of rate enables people to make everyday choices, such as the choice of phone plan, housing loan and many more (Glazer \& McConnell, 2002; Lamon, 1999). Despite considerable research in the area, it remains a troublesome concept to teach and learn (Orton, 1983; Kaput \& Schorr, 2002; Ubuz, 2007). A mapping of existing conceptions of rate held by middle secondary school students provides insights into the possible basis of these difficulties.

An examination of the ways in which these conceptions differ from important aspects of rate required for students to develop a mathematical concept as it is generally understood and accepted by experts, provides important information to educators. This study aimed to identify these educationally critical aspects (ECA) of 'rate' through a phenomenographic investigation of the range of conceptions of rate held by a group of Australian Year 10 (middle secondary) students from the state of Victoria. This is the first time this concept has been explored from a phenomenographic perspective and demonstrates, in one setting, the efficacy of phenomenography to explore mathematical conceptions.

This approach revealed eight categories of conceptions of rate leading to four ECA of rate. The full spectrum of students' conceptions revealed in the phenomenographic interviews is presented in the form of an outcome space (shown in Figure 11 and discussed below). This is followed by an analysis of these conceptions to identify the ECA of rate which may guide educators to assist students to correct and extend their understanding of rate and so, at least informally, better match the concept of rate encapsulated in mathematical definitions. Particular emphasis, in this paper, is placed on the description of the use of phenomenography in revealing the conceptions of rate held by Year 10 students.

This study both confirms the notion that rate is a complicated concept and also informs teachers of the different ways, both correct and incorrect, in which students conceive this difficult mathematical idea.

\section{Background}

"[V]irtually the entire population is now deemed to be in need of significant mathematical power" (Kaput, 1992, p. 518). Understanding rate is one aspect of this significant mathematical power to which Kaput refers. It enables people to make everyday choices, for example: which path to take given the slope of terrain taken from a map; what to buy given, for example, price per orange; and many more (Glazer \& McConnell, 2002; Lamon, 1999). The notion of variable rate is assuming more importance, for example, house mortgages where rates often vary considerably over time and home buyers find that the affordable repayments, quoted at the start of a loan, become prohibitive when rates change.

Few research studies have been conducted that probe pre-calculus students' understanding of rate. Bell and Onslow (1987) tested 598 British secondary students, aged 11 to 14 years, who had not studied calculus. Their results indicate that students showed "considerable confusion concerning the numerator/denominator roles of the two quantities comprising a rate" (p.275). Other research with students of a similar age and stage explored students' understanding of specific applications of the concept of rate, for example: Kaput and Schorr (2002) - speed; Smith, Maclin, Grosslight and Davis (1997) - density; Stump (2001) - gradient; and Tourniare and Pulos (1985) - proportion. Kaput and Schorr (2002) report that representational infrastructures afforded by technology assisted students to develop their conceptual understanding of the mathematics of change and motion in ways not previously available to them. Smith et al. (1997) advocate shifting the focus of instruction from textcentred, quantitative approaches to approaches which take into account students' starting conceptions and build on their existing qualitative notions moving towards more complete quantitative conceptions of density. Stump (2001) advises that few students used the slope of a line to measure the rate of change of variables involved in functional contexts. Tourniare and Pulos (1985) demonstrate that the development of proportional thinking is complex and strategies for solving problems involving proportional thinking become more correct and sophisticated over time. Whilst this previous research provides important background, the study reported on in this article encompasses a wider exploration of participants' conceptions of rate than those discussed above. It includes students' correct as well as incorrect thinking and considers notions of variable rate as well as constant rate. In addition to understanding of rate in everyday contexts, a sophisticated mathematical understanding of rate is 
crucial to the development of understanding of derivative (Bezuidenhout, 1998; Oliveros \& SantosTrigo, 1997; Asiala, Cottrill, Dubinsky, \& Schwingendorf, 1997). Derivative is an important calculus concept requiring more than just procedural competence (Tall, 1985). Calculus students' difficulties with rate manifest in many forms. One of the most significant of these is the confusion between the rate and the extensive quantities which constitute it (Thompson, 1994; Rowland \& Jovanoski, 2004), for example, understanding of speed as a distance. Lopez-Gay, Martinez-Torregrosa, Gras-Marti and Torregrosa (2002), in their study of 103 high school physics teachers and analysis of 38 Physics text books, stress the importance of students' understanding of differential calculus in understanding physics. They claim that physics students don't understand the use of calculus in simple real-world problems and have difficulty in applying it with autonomy. This suggests that the value of calculus to other fields of study is undermined by students' lack of conceptual understanding of it. Bingolbali and Monaghan (2008) report that the tertiary participants in their study were influenced in their concept images of derivative by differences in the teaching practices of mathematics and engineering departments. Mathematics students focussed on tangent aspects of derivative whereas engineering students focussed on rate of change aspects.

Quantitative methods, such as surveys and testing, have previously been used to examine calculus students' understanding of rate (see for example Orton, 1983; Ubuz, 2001). Whilst quantitative methods have proved to be valuable in highlighting the difficulties with the concept of rate experienced by some calculus students, we have seen this issue of a lack of understanding of rate persist over a long period of time. Ubuz (2007) calls for research to "enhance the understanding of the conceptualizations of calculus students" claiming "there is a need to deepen our understanding of students' prior knowledge about calculus and pre-calculus concepts and how that knowledge can serve as an anchor for subsequent learning" (p.635).

Piaget (1970) suggested developmental stages for children's understanding of speed and several researchers have offered frameworks for analysing students' understanding of derivative (Asiala et al., 1997; delos Santos \& Thomas, 2003; Zandieh, 2000). This study seeks to establish a similar structure for rate by determining the conceptions of rate of this study's participants based on empirical evidence from interviews. A fresh approach seemed appropriate in order to specifically identify and categorise the conceptions of rate held by Year 10 students and so better understand the prior knowledge such students bring to the study of calculus. We chose to adopt a qualitative methodology rather than conduct a quantitative study because it seemed important to take an open approach, founded in the empirical data, in order to capture the students' thinking rather than assess their responses to the views of experts.

\section{Methodology}

There are many qualitative methodologies from which to choose. Phenomenography was employed as a methodology in this study because of its structured approach which had demonstrated efficacy in research in a range of other educational contexts (see for example Marton, Runesson, \& Tsui, 2004). Phenomenography systematically describes a limited number (Marton, 1988) of qualitatively different categories based on the responses of the group as a whole, providing "a description on the collective level, and in that sense individual voices are not heard" (Marton \& Booth, 1997, p.114). It is an interpretive research approach which describes a phenomenon as seen by the participants, so the object of the research is to reveal the variation the conceptions of the phenomenon under investigation (Marton, 1988), such as, the concept of rate. It is important to emphasise that a phenomenographic researcher attempts to describe a phenomenon as others see it, not as it is seen by the researcher. As will be explained below, the aim of phenomenography is to reveal categories of description delineated by the dimensions of variation which emerge from the data and hence, structure the categories into an outcome space.

The process of phenomenographic analysis begins with taking meaningful quotes relating to the phenomenon from the individual transcripts which are then pooled, shifting attention from the individual to the meanings expressed by the group as a whole (Marton, 1988). The categories or themes emerge from the analysis of the transcripts rather than the researcher forcing the data to fit into a predetermined model. Typically, transcriptions of interviews are examined to find ways of grouping the participants' responses into these categories of description according to the features and characteristics which they hold in common. These features and characteristics are referred to as the dimensions of variation. These dimensions delineate the categories one from another according to the number of dimensions or values of dimensions which are evident in each category (Cope, 2000). However, the categories and dimensions are so interrelated that it is difficult to discuss one without reference to the other. The initial categories suggest the initial dimensions and the data is repeatedly re-examined to 
refine both the categories and the dimensions. This leads to a clearer definition of the dimensions and the possible values that they could take. At each iteration, an attempt is made to differentiate each category from other categories on the basis of the dimensions. The dimensions facilitate an ordering of the categories into an outcome space where each category is placed in relationship to the other categories.

The initial categories are recognised in the data in much the same way as themes are identified in a grounded theory approach. In grounded theory, the categories or themes emerge from the open coding of the transcripts whereas in phenomenography the categories are developed through consideration of pooled, de-identified, discourse fragments providing a description on the collective level. "[A]nalysis [is] focused on key aspects of the collective experience" (Akerlind, Bowden \& Green, 2005, p. 82), concentrating on the phenomenon under investigation as seen by the participants. The 'pool of meanings' approach enables greater decontextualisation of the data, thus facilitating the "phenomenographic focus on collective meanings, and away from individual meanings" (p.92). So, "categories of description are not intended to necessarily correspond to the perception of any particular individual ... [rather they are an] aggregate of similar perceptions ... [where] texts [are examined] as a group rather than singularity of individual experience ... [so that] any one transcript could contribute to a number of categories" (Akerlind et al., 2005, p. 92). Like grounded theory, phenomenography also seeks to reveal the finite set of categories of conceptions of a phenomenon, but it is different from grounded theory because the categories are logically connected in a hierarchical outcome space structured according to the dimensions, thus inferring that some categories indicate a higher level of perception of the phenomenon in question (Bowden, 1994; Marton, 1988). Phenomenography and grounded theory have much in common but, as a methodology, phenomenography is closely prescribed at every stage. For a phenomenographic study "the validity of the outcomes is related to the processes that are used at all stages" (Akerlind et al., 2005, p. 89), that is: the selection of the sample for maximum variation; the conduct of consistent, open interviews; and the iterative analysis focused on the meanings expressed in the pooled discourse fragments leading to an outcome space reflective, not of individuals, but of the whole group.

The results of phenomenographic study may be further employed to determine the educationally critical aspects (ECA) of the phenomenon. According to Cope (2000), ECA are "aspects of the experience of learning about a phenomenon that are educationally critical to developing the complexity of ways of experiencing a phenomenon (equivalent to depth of understanding) desired by the teacher" (p. 35). Determining ECA involves the comparison of experts' conception of the phenomenon and the conceptions of the phenomenon held by the learners. In the case of this study, this means a comparison of the conceptions of rate found in the data and summarised in the outcome space with elements of an expert's concept of rate as it is encapsulated in mathematical definitions.

\section{This Study}

The decision to employ phenomenography to investigate conceptions of rate directly influenced the manner of data collection. Rigorous guidelines have been established about the conduct of phenomenographic interviews, where the researcher endeavours to gain as much information as possible about each participant's conceptions, for later analysis.

The participants of a phenomenographic study are chosen in order to maximise the variation in perceptions of the phenomenon, rather than to provide a statistically representative sample (Akerlind et al., 2005). The participants in this study were twenty Year 10 students. These students were appropriate participants for this research because, according to the Victorian Essential Learning Standards (VCAA, 2007) these participants, in Year 10, may be expected to have previously studied constant rate and some functions where rate varies, such as quadratic, exponential and logarithmic functions. It was expected that they would provide a variety of responses because they attended five different schools that differed in the following ways: state schools; independent schools; girls' schools; co-educational schools; regional schools; schools in the outer-suburban fringe of Melbourne, inner-city and suburbs with a high level of cultural diversity.

In phenomenographic research, probing interviews are usually conducted and transcribed from the audio-record in as much relevant detail as possible. In this study, video was used for data collection because the combination of utterances and gestures have the potential to give greater insight into students' thinking (see Herbert \& Pierce, 2007 for more detail about the collection and interpretation of video data for phenomenographic analysis of the interview data of this study).

The interviews consisted of a discussion of interactive computer simulations of real-world contexts involving rate: a window partially covered by a blind, in Geometer's Sketchpad (Figure 1); and characters walking, in JavaMathWorld (Figure 2). The simulated real-world contexts are shown along 
with multiple mathematical representations of the functions involved in the simulations. In making the choice to use these specific contexts, consideration was given to Akerlind's (2005) advice that "an individual's experience of a phenomenon is always embedded within a particular context, and a different context may bring different aspects of the phenomenon into awareness" (p.106). However, due to the time constraints on the length of the interviews, the simulations presented were restricted to only two contexts. Analysis of typical text book rate examples revealed two main context types: those involving distance and time and those involving other variables. Our choice of simulations reflected this dichotomy.

The simulations displayed on the computer provided all participants with the same contexts to discuss. The use of the computer simulations allowed the young participants to focus on the screen, to assist them to be more relaxed than would be the case in a face-to-face interview. The interactive nature of the simulations also allowed the participants a measure of control over the interviews. Using the simulations helped formulate their descriptions, especially if they had difficulty expressing their ideas.

The GSP simulation shows a schematic diagram of a blind partially shading a rectangular window and a schematic diagram showing a blind partially shading a non-rectangular window (Figure 1). The position of the blind could be changed, with the effect on the variables of area of sunlight and height of blind above the bottom of the window. This effect was illustrated in the multiple mathematical representations, numeric, graphic and symbolic, of constant rate associated with the simulation involving the rectangular window. Participants were shown the rule, the graph and the table, in that order, and asked what each representation told them about the rate the area was changing. Similarly, a blind shading a non-rectangular window was used to probe participants' understanding of the differences between constant and variable rate. In this way the use of GSP facilitated exploration of constant and variable rate, in the numeric, graphic and symbolic representations, in a context where the rate is considered in terms of the variables area and height.

In JMW, files were prepared simulating actors, a frog and a clown, walking at constant rate and also variable rate. They watched the frog and clown walking at constant rate and saw the associated multiple mathematical representations, numeric, graphic and symbolic. The interviewer then asked who was walking faster, the frog or the clown. Next they were shown a file with the frog accelerating. The participants were asked to describe the rate the frog was walking. In this way, JMW facilitated exploration of constant and variable rate, in the numeric, graphic and symbolic representations, in a context where the rate is considered in terms of the variables distance and time.

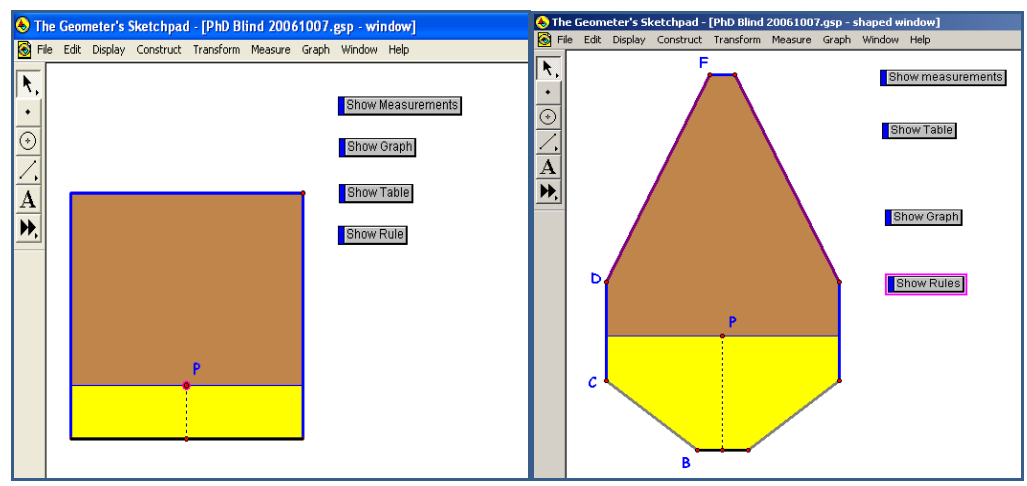

Figure 1: GSP screen of diagram of a blind shading two windows

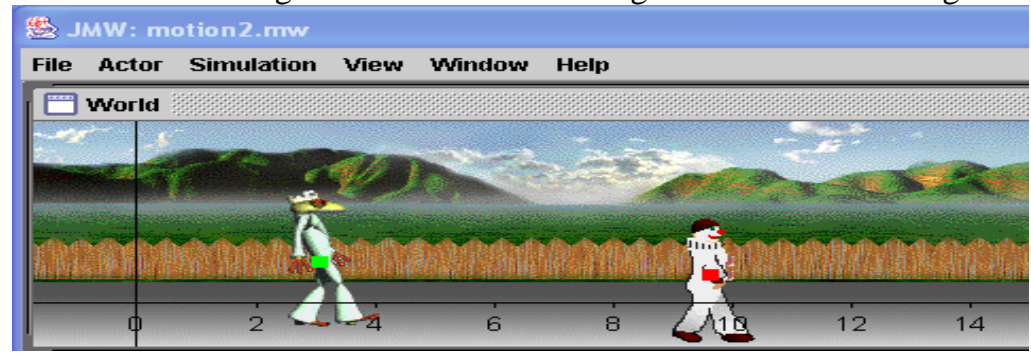

Figure 2: JMW screen with frog \& clown walking

For each context, participants were shown the numeric, graphic and symbolic representations one at a time to avoid cognitive overload. The initial interview question was always the very open "what can you tell me about the rate from the.....?". Follow up questions were dependent on the participant's response. Participants were free to interact with the simulations in any way they chose. The video recordings of the interviews were digitised and examined, along with the transcriptions, for evidence of 
conceptions of rate. Phenomenographic analysis, consisting of the refinement of the categories through an iterative process involving repeated reference to the interview transcripts and videos, was then undertaken.

\section{Results}

The analysis of the interview data resulted in the constitution of the outcome space (see Figure 11). It consists of eight categories that are illustrated by examples of excerpts from student interviews. During analysis of the data, four main ways (referred to as 'dimensions of variation') to discriminate between the categories emerged: Focus on word 'rate'; Focus on variables; Focus on relationship between variables; and Focus on nature of related variables. For example, in Category B, only awareness of rate as a numeric quantity of the dimension of variation Focus on word 'rate' is discerned. No other dimensions or their values are recognised. The relationship between the categories of description and the dimensions of variation is summarised at the beginning of the description of each category (Figures 3 to 10 ).

In the first dimension Focus on word 'rate' may take values 'quality' and 'quantity'. These values differentiate between the conceptions where 'rate' is experienced as a numeric quantity or rating of a quality. This dimension reflects an emphasis on the word 'rate' and whether the word brings awareness of rate as a numeric quantity. The second dimension Focus on variables may take values 'one' and 'two' and refers to the number of variables. The discernment of two changing variables is a critical aspect in the discernment of rate as a relationship. This dimension describes the bridge from 'incorrect' conceptions of rate to 'correct' mathematical conceptions of rate.

The third dimension Focus on relationship between variables may take values 'qualitative', 'quantitative-constant', 'quantitative-variable' and refers to the nature of the description of the relationship between the variables. These values differentiate between the conceptions where 'rate' is experienced as a relationship between two changing quantities. This dimension separates the different 'correct' but incomplete conceptions of rate. The fourth dimension Focus on nature of related variables may take values 'distance and time' and 'both contexts' and refers to the context in which the concept of rate is explored. This dimension was considered necessary as evidence from the transcripts indicated that rate could be discerned in the Distance-Time context, but not in the Area-Height context. These values differentiate between the conceptions where the context of the rate differs. Although, we have only explored participants' conceptions of rate in two particular contexts, this dimension suggests a separation of 'correct' motion-dependant conceptions of rate from 'correct' conceptions of rate which are transferable to another context.

The categories, which emerged from the data of this study, are described below. The categories are listed from least complex to most complex. Categories that are more complex than others include more aspects of awareness than less complex categories. More complex categories may also be seen as more complete and closer to a correct mathematical definition of rate.

\begin{tabular}{|c|c|c|c|}
\hline $\begin{array}{l}\text { Focus on word } \\
\text { 'rate' }\end{array}$ & $\begin{array}{l}\text { Focus } \\
\text { variables }\end{array}$ & $\begin{array}{l}\text { Focus on } \\
\text { relationship } \\
\text { between } \\
\text { variables }\end{array}$ & $\begin{array}{l}\text { Focus on nature } \\
\text { of } \quad \text { related } \\
\text { variables }\end{array}$ \\
\hline quality & One & Qualitative & Distance \& time \\
\hline numeric & Two & $\begin{array}{l}\text { Quantitative } \\
\text { constant }\end{array}$ & Both contexts \\
\hline & & $\begin{array}{l}\text { Quantitative } \\
\text { variable }\end{array}$ & \\
\hline
\end{tabular}

Figure 3: Values of dimensions in Category A

In this category, rate is experienced as an ordered set of values assessing the worth of a quality, such as the judgements of an item for sale as 'poor', 'fair', 'good', 'very good' or 'excellent' which indicate increasing values reflecting the condition of the item. The word 'rate' may have been heard in a variety of contexts, but is associated with real-world judgements of quality, so the dimension of Focus on word 'rate' is discerned to have a value of 'quality'

$\boldsymbol{R}$ : Can you give me an example [of rate]?

I20: Ratings on movies and stuff. 
Category B: Rate is experienced as a word associated with a numeric value

\begin{tabular}{|l|l|}
\hline $\begin{array}{l}\text { Focus on word } \\
\text { 'rate' }\end{array}$ & $\begin{array}{l}\text { Focus on } \\
\text { variables }\end{array}$ \\
\hline quality & One \\
\hline numeric & Two \\
\hline
\end{tabular}

\begin{tabular}{|l|}
\hline $\begin{array}{l}\text { Focus on } \\
\text { relationship } \\
\text { between } \\
\text { variables }\end{array}$ \\
\hline Qualitative \\
\hline $\begin{array}{l}\text { Quantitative } \\
\text { constant }\end{array}$ \\
\hline $\begin{array}{l}\text { Quantitative } \\
\text { variable }\end{array}$ \\
\hline
\end{tabular}

\begin{tabular}{|l|}
\hline $\begin{array}{l}\text { Focus on nature } \\
\text { of related } \\
\text { variables }\end{array}$ \\
\hline Distance \& time \\
\hline Both contexts \\
\hline
\end{tabular}

Figure 4: Values of dimensions in Category B

In this category, rate is experienced as a word. This word exists in the vocabulary associated with a numerical quantity, so the dimension of Focus on word 'rate' is discerned to have a value of 'numeric'. Awareness of the ordinal nature of numbers is present. The word may have been heard in a variety of contexts, for example, real-world encounters or classroom experiences. The word 'rate' belongs to the collection of words developed through these experiences.

$\boldsymbol{R}:$ what is rate? [pause] can you give me an example of rate?

I3: Well there is that bank rate thing. Well they add rate if you don't pay your bills or something on time on time, they keep adding.

Category $C$ : Rate is experienced as a single quantity

\begin{tabular}{|l|l|}
\hline $\begin{array}{l}\text { Focus on word } \\
\text { 'rate' }\end{array}$ & $\begin{array}{l}\text { Focus on } \\
\text { variables }\end{array}$ \\
\hline quality & One \\
\hline numeric & Two \\
\hline
\end{tabular}

\begin{tabular}{|l|}
\hline $\begin{array}{l}\text { Focus on } \\
\text { relationship } \\
\text { between } \\
\text { variables }\end{array}$ \\
\hline Qualitative \\
\hline $\begin{array}{l}\text { Quantitative } \\
\text { constant }\end{array}$ \\
\hline $\begin{array}{l}\text { Quantitative } \\
\text { variable }\end{array}$ \\
\hline
\end{tabular}

\begin{tabular}{|l|}
\hline $\begin{array}{l}\text { Focus on nature } \\
\text { of related } \\
\text { variables }\end{array}$ \\
\hline Distance \& time \\
\hline Both contexts \\
\hline
\end{tabular}

Figure 5: Values of dimensions in Category C

Rate is experienced in terms of single quantity which may change, so the dimension of Focus on variables is discerned to have a value of 'one'. The magnitude of the rate is seen as a single entity with no relationship to any other quantities. This category is characterised by the awareness that rate has something to do with change. This awareness of change is an important stage in the development of the concept of rate.

$\boldsymbol{R}:$ tell me about the rate the area is changing.

I12 : It's getting greater.

$\boldsymbol{R}$ : What's getting greater?

I12: Like, the area of sunlight's getting greater

$\boldsymbol{R}$ : can you tell me about the rate that the clown is walking? You can make him walk as often as you like.

I14:He's walking at about 8 seconds.

Category D: Rate is experienced as the result of a formula calculation without recognition of the relationship between quantities

\begin{tabular}{|l||l|l|}
\hline $\begin{array}{l}\text { Focus on word } \\
\text { 'rate' }\end{array}$ & $\begin{array}{l}\text { Focus on } \\
\text { variables }\end{array}$ & $\begin{array}{l}\text { Focus on } \\
\text { relationship } \\
\text { between } \\
\text { variables }\end{array}$ \\
\hline quality & One \\
\hline numeric & Two \\
\hline $\begin{array}{l}\text { Qualitative } \\
\text { constant }\end{array}$ \\
\hline $\begin{array}{l}\text { Quantitative } \\
\text { variable }\end{array}$ \\
\hline
\end{tabular}

\begin{tabular}{|l|}
\hline $\begin{array}{l}\text { Focus on nature } \\
\text { of related } \\
\text { variables }\end{array}$ \\
\hline Distance \& time \\
\hline Both contexts \\
\hline
\end{tabular}

Figure 6: Values of dimensions in Category D

Rate is experienced as the result of a formula calculation where a value is substituted into a given rate formula, so the dimension of Focus on variables is discerned to have a value of 'two'; the substituted value; and the resulting value. The formula calculation is seen as an academic exercise, something the teacher wishes a student to complete. Rate is seen as one fixed answer to the academic exercise of substituting a value in a formula. It is not seen as expressing a relationship between the value substituted and the result of the calculation, focus is on the result. There is awareness that the 
result of the calculation may vary, so the rate may take a variety of discrete values depending on the value substituted into the formula.

$\boldsymbol{R}:$ What is rate? [pause] Can you give an example of rate?

I2: if you gave me a problem [formula], I could substitute the numbers in it and then I would be able to give you a rate.

Category E: Rate is experienced as a relationship between changes in two quantities.

\begin{tabular}{|c|c|c|c|}
\hline $\begin{array}{l}\text { Focus on word } \\
\text { 'rate' }\end{array}$ & $\begin{array}{l}\text { Focus on } \\
\text { variables }\end{array}$ & $\begin{array}{l}\text { Focus on } \\
\text { relationship } \\
\text { between } \\
\text { variables }\end{array}$ & $\begin{array}{l}\text { Focus on nature } \\
\text { of related } \\
\text { variables }\end{array}$ \\
\hline Quality & One & Qualitative & Distance \& time \\
\hline \multirow[t]{2}{*}{ Numeric } & \multirow[t]{2}{*}{ Two } & $\begin{array}{l}\text { Quantitative } \\
\text { constant }\end{array}$ & Both contexts \\
\hline & & $\begin{array}{l}\text { Quantitative } \\
\text { variable }\end{array}$ & \\
\hline
\end{tabular}

Figure 7: Values of dimensions in Category E

Rate is experienced as some kind of qualitative relationship connecting the two rate-related quantities, so the dimension of Focus on variables is discerned to have a value of 'two' and the dimension of Focus on relationship between variables is discerned to have a value of 'qualitative'. Both quantities involved in the rate are acknowledged. Change in two quantities is focal in awareness. A relationship between the changes in the two quantities is discerned and expressed with words assigned to describe the scale for the rate, for example, faster or increases. This way of experiencing rate is discerned in a variety of contexts.

I3: As area of sunlight increases, height of the blind also increases.

I6: You can tell the clown has walked more quickly because his distance is greater for the period of time.

Category F: Rate is experienced as a constant numeric relationship between changes in two quantities.

\begin{tabular}{|l|l|}
\hline $\begin{array}{l}\text { Focus on word } \\
\text { 'rate' }\end{array}$ & $\begin{array}{l}\text { Focus on } \\
\text { variables }\end{array}$ \\
\hline Quality & One \\
\hline Numeric & Two \\
\hline
\end{tabular}

\begin{tabular}{|l|}
\hline $\begin{array}{l}\text { Focus on } \\
\text { relationship } \\
\text { between } \\
\text { variables }\end{array}$ \\
\hline Qualitative \\
\hline $\begin{array}{l}\text { Quantitative } \\
\text { constant }\end{array}$ \\
\hline $\begin{array}{l}\text { Quantitative } \\
\text { variable }\end{array}$ \\
\hline
\end{tabular}

\begin{tabular}{|l|}
\hline $\begin{array}{l}\text { Focus on nature } \\
\text { of related } \\
\text { variables }\end{array}$ \\
\hline Distance \& time \\
\hline Both contexts \\
\hline
\end{tabular}

Figure 8: Values of dimensions in Category $\mathrm{F}$

In this category, rate is accepted as a mathematical concept with specific numeric values assigned to the two rate-related quantities and the rate, in a variety of circumstances where the rate is constant. There is a simultaneous awareness of the two quantities and their relationship, so the dimension of Focus on variables is discerned to have a value of 'two' and the dimension of Focus on relationship between variables is discerned to have a value of 'quantitative constant'.

$\boldsymbol{R}$ : what makes you think he is walking faster?

I3: Because the metres that he walks is bigger rather than being smaller. With the frog, the less metres that he covers [pause]. The clown in 1 meter he's reached 5, I mean in 1 second he's reached 5 metres rather than the frog in 1 metre he goes 3 metres, I mean one second he's reached 3 meters.

I7: the area increases by a rate of 3.2 for every 0.5 .

Category G: Rate is experienced as a numeric relationship between the changes in distance and time i.e. speed.

\begin{tabular}{|l|l|}
\hline $\begin{array}{l}\text { Focus on word } \\
\text { 'rate' }\end{array}$ & $\begin{array}{l}\text { Focus on } \\
\text { variables }\end{array}$ \\
\hline Quality & One \\
\hline Numeric & Two \\
\hline
\end{tabular}

\begin{tabular}{|l|}
\hline $\begin{array}{l}\text { Focus on } \\
\text { relationship } \\
\text { between } \\
\text { variables }\end{array}$ \\
\hline Qualitative \\
\hline $\begin{array}{l}\text { Quantitative } \\
\text { constant }\end{array}$ \\
\hline $\begin{array}{l}\text { Quantitative } \\
\text { variable }\end{array}$ \\
\hline
\end{tabular}

\begin{tabular}{|l|}
\hline $\begin{array}{l}\text { Focus on nature } \\
\text { of related } \\
\text { variables }\end{array}$ \\
\hline Distance \& time \\
\hline Both contexts \\
\hline
\end{tabular}

Figure 9: Values of dimensions in Category $\mathrm{G}$

In this category, rate is experienced as speed, so the dimension of Focus on nature of related variables is discerned to have a value of 'distance \& time'. The relationship between the quantities of 
distance and time is recognised as both qualitative and quantitative. In this category, both constant rate and variable rate are recognised as both qualitative and quantitative relationship between distance and time and so is dependent on a motion context.

$\boldsymbol{R}:$ What is rate?

I5: [pause] Like how fast things are going?

I10: He's walking about four meters per second...the rate he is walking remains the same.

I1: he [the clown] walks a 22 meters in 7 seconds and then he [the frog] only makes 7 meters in 7 seconds.

Category H: Rate is experienced as a numeric relationship between the changes in any two quantities

\begin{tabular}{|l|l|}
\hline $\begin{array}{l}\text { Focus on word } \\
\text { 'rate' }\end{array}$ & $\begin{array}{l}\text { Focus on } \\
\text { variables }\end{array}$ \\
\hline Quality & One \\
\hline Numeric & Two \\
\hline
\end{tabular}

\begin{tabular}{|l|}
\hline $\begin{array}{l}\text { Focus on } \\
\text { relationship } \\
\text { between } \\
\text { variables }\end{array}$ \\
\hline Qualitative \\
\hline $\begin{array}{l}\text { Quantitative } \\
\text { constant }\end{array}$ \\
\hline $\begin{array}{l}\text { Quantitative } \\
\text { variable }\end{array}$ \\
\hline
\end{tabular}

\begin{tabular}{|l|}
\hline $\begin{array}{l}\text { Focus on nature } \\
\text { of related } \\
\text { variables }\end{array}$ \\
\hline Distance \& time \\
\hline Both contexts \\
\hline
\end{tabular}

Figure 10: Values of dimensions in Category $\mathrm{H}$

In this category, both constant and variable rate are experienced as numeric relationships between changes in two quantities. So in this category, rate is experienced as a versatile concept that can be applied to both contexts; described verbally in narrative terms; and quantified from information supplied in a graph or table. The context may involve constant or variable rate.

14: That's increasing, so that it [area] starts off small 1 and it goes up to 2.6, so that's 1.6, the difference, then the next one is 2.2 the difference and the one after that is 2.8 the difference

Category $\mathrm{H}$, where rate is experienced as a numeric relationship between the changes in any two quantities, including distance and time, encompasses all the possible aspects of rate which could be expressed by students at Year 10 who have not begun a study of calculus.

\section{Outcome Space}

The hierarchy of the outcome space was based on the values of the dimensions taken by each category as can be seen in Figures 3 to 10. They provide evidence for the proposed hierarchy of the outcome space seen in Figure 11, This illustrates the inclusive nature of the expanding awareness seen in the four dimensions. There may be other aspects of the phenomenon of rate which are not exposed in this outcome space, but in a phenomenographic study only those categories which are supported by the data can be included in the outcome space.

\section{Educationally Critical Aspects}

A formal description of rate that is accepted by mathematicians (see for example a typical tertiary text Stewart (2007)) encompasses the notion of 'instantaneous rate' as equivalent to the gradient of the tangent to a curve at a given point and is developed from the notion of 'average rate' or the 'gradient' of the straight line joining two points on a curve. It subsumes the notion of constant rate as a special example where the instantaneous rate is the same for all points on a curve, in this case a straight line and is an abstract conception of rate comprising both constant and variable rate and can be discerned and applied in any context. In higher levels of mathematics, derivative is synonymous with instantaneous rate. Stewart (2007) presents the standard definition stating "the derivative of a function

f at a number a" to be $\lim _{h \rightarrow 0}(f(a+h)-f(a)) / h(\mathrm{p} .77)$. This formal definition draws attention to the ratio of quantitative change in two variables as the change in the second variable approaches zero. The formal definition completely encapsulates the ideas that an expert would be expected to include in their description. They might take several sentences to do this without reciting the formula but would include the ideas mentioned above.

Since Category $\mathrm{H}$ encompasses all the possible aspects of rate which could be expressed by students at Year 10 who have not begun a study of calculus, this conception of rate will be taken as an adequate conception for this age and stage for the purpose of identifying the ECA of rate. 


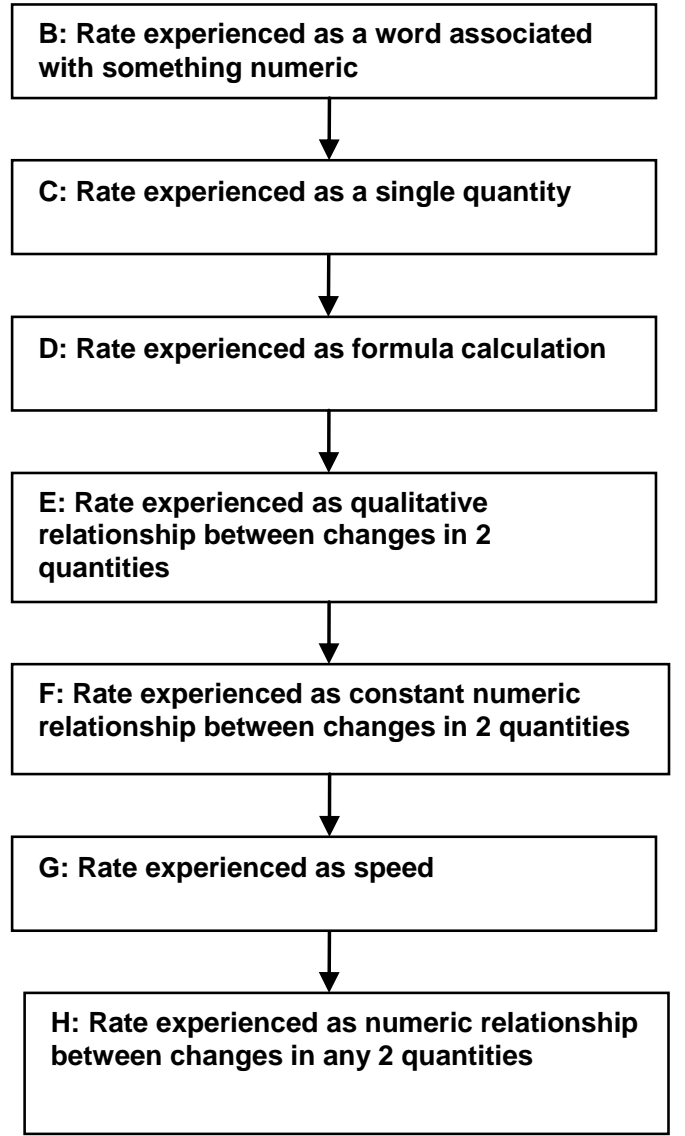

Figure 11: The Rate Outcome Space

Each category of description in the outcome space is compared with the conception of rate expressed in Category $\mathrm{H}$ to determine the ECA of rate. The comparison is intended to ascertain where each category diverges from this conception. Table 1 provides a list of the categories, in reverse order, and identifies any aspects missing from the category when compared with Category H. As the categories form a hierarchical outcome space based on consideration of the dimensions, aspects missing from one category are also missing from the all subsequent categories. For example, 'Transfer between contexts' are missing from Category $\mathrm{G}$, so these aspects are also missing from Category $\mathrm{F}$ and, in addition, 'Variable rate' is another gap identified in this category. Categories E, F and G may be considered as mathematically correct, but incomplete, whereas Categories A to D show various degrees of an incorrect, as well as incomplete, understanding of rate.

In the comparison of the categories (see Table 1) with Category H's conception of rate used as a baseline, the words shown in bold indicate additional missing components from those belonging to the previous category. The dimensions and their values along with the categories' comparison with the Category $\mathrm{H}$, together suggest the ECA of rate. In particular, the notion of a numeric relationship between the changes in any two variables (not only distance and time) and the awareness that this relationship may not be constant seem especially important in the development of a robust conception of rate.

The ordering of the dimensions and the values they may take should not be seen as a developmental map, but provide a way of interpreting and structuring the comparison seen in Table 1 in order to identify the ECA of rate. These ECA provide guidance for the development of suitable teaching material and learning activities which specifically address these critical aspects. 
Table 1: Comparison of categories with Category $\mathrm{H}$

\begin{tabular}{|c|c|c|c|}
\hline \multicolumn{2}{|r|}{ Category } & Missing component(s) & Commentary \\
\hline G & $\begin{array}{l}\text { Rate is experienced as a } \\
\text { numeric relationship between } \\
\text { changes in distance and time } \\
\text { i.e. speed. }\end{array}$ & Transfer between contexts & $\begin{array}{l}\text { This conception of rate is confined to the context of } \\
\text { motion. Both constant and variable rate are } \\
\text { discerned as speed and acceleration. Transference } \\
\text { to other contexts is inhibited by this conception of } \\
\text { rate, hence is not an abstract conception of rate } \\
\text { independent of context. }\end{array}$ \\
\hline $\mathrm{F}$ & $\begin{array}{l}\text { Rate is experienced as a } \\
\text { constant numeric relationship } \\
\text { between changes in two } \\
\text { quantities. }\end{array}$ & $\begin{array}{l}\text { Transfer between contexts, } \\
\text { Variable rate }\end{array}$ & $\begin{array}{l}\text { This conception of rate acknowledges the existence } \\
\text { of a numeric relationship between changes in the } \\
\text { variables in circumstances where the rate is } \\
\text { constant. Variable rate is not quantified in any way, } \\
\text { although limited awareness of some relationship is } \\
\text { shown. }\end{array}$ \\
\hline $\mathrm{E}$ & $\begin{array}{l}\text { Rate is experienced as a } \\
\text { relationship between changes } \\
\text { in two quantities. }\end{array}$ & $\begin{array}{l}\text { Transfer between contexts, } \\
\text { Variable rate, Quantification }\end{array}$ & $\begin{array}{l}\text { This conception of rate acknowledges the existence } \\
\text { of some relationship between the changes in the } \\
\text { variables, but this relationship cannot be quantified } \\
\text { even for cases of constant rate. }\end{array}$ \\
\hline $\mathrm{D}$ & $\begin{array}{l}\text { Rate is experienced as the } \\
\text { result of a formula } \\
\text { calculation without } \\
\text { recognition of the } \\
\text { relationship between } \\
\text { quantities }\end{array}$ & $\begin{array}{l}\text { Transfer between contexts, } \\
\text { Variable rate, Relationship }\end{array}$ & $\begin{array}{l}\text { This conception of rate does not acknowledge the } \\
\text { existence of any relationship between the variables. } \\
\text { Rate is seen as a single, static quantity which is the } \\
\text { result of a formula calculation. This way of seeing } \\
\text { rate may be a consequence of early instruction in } \\
\text { rate where the formula is emphasised, without } \\
\text { reference to the context and the relationship } \\
\text { between variables not stressed. }\end{array}$ \\
\hline $\mathrm{C}$ & $\begin{array}{l}\text { Rate is experienced as a } \\
\text { single quantity }\end{array}$ & $\begin{array}{l}\text { Transfer between contexts, } \\
\text { Variable rate, Two variables }\end{array}$ & $\begin{array}{l}\text { This conception of rate does not acknowledge the } \\
\text { existence of any relationship between the variables. } \\
\text { Rate is seen as a single quantity, with a focus on } \\
\text { only one of the variables or perhaps speed as a } \\
\text { single entity rather than a relationship between } \\
\text { distance and time. This may be a result of prior } \\
\text { experiences with speed as a reading on a } \\
\text { speedometer. }\end{array}$ \\
\hline B & $\begin{array}{l}\text { Rate is experienced as a } \\
\text { word associated with a } \\
\text { numeric value }\end{array}$ & $\begin{array}{l}\text { Transfer between contexts, } \\
\text { Variable rate, Quantification, } \\
\text { Two variables, Relationship, } \\
\text { Change, Calculation }\end{array}$ & $\begin{array}{l}\text { This conception of rate does not acknowledge the } \\
\text { existence of any relationship between the variables. } \\
\text { Rate is seen as a single, static quantity as term } \\
\text { remembered from earlier mathematics classes or in } \\
\text { every-day conversation, such as on the TV news. } \\
\text { This way of seeing rate is not linked to any numeric } \\
\text { calculation and may be a consequence of early } \\
\text { instruction in rate where relationship between } \\
\text { variables was not stressed and the formula is } \\
\text { forgotten. }\end{array}$ \\
\hline A & $\begin{array}{l}\text { Rate is experienced as a } \\
\text { word judging a quality. }\end{array}$ & $\begin{array}{l}\text { Transfer between contexts, } \\
\text { Variable rate, Quantification, } \\
\text { Two variables, Relationship, } \\
\text { Change, Calculation, Numeric } \\
\text { association, Something to do } \\
\text { with maths }\end{array}$ & $\begin{array}{l}\text { This conception of rate is not related to } \\
\text { mathematics. Even ratings involving numbers, such } \\
\text { as rating the taste of food from } 1 \text { to } 5 \text {, only involves } \\
\text { assigning numbers to grade the quality. The word } \\
\text { 'rate' is associated with rating some real-world } \\
\text { item or event, For example, rating of } \\
\text { accommodation using stars. }\end{array}$ \\
\hline
\end{tabular}

Students need to be able to recognise that the word 'rate' has two different meanings and the mathematical conception of rate involves the relationship between the changes in two quantities. The discernment of two quantities is necessary before a relationship between changes in them can be appreciated. An awareness of such a relationship is crucial in experiencing rate as experts in the community of practice experience it, so this relationship is an ECA of rate. Another ECA is the possibility that rate may vary. Whilst it is expected that students of this age and stage would be aware that rates in real-world contexts do vary, such as speed, tax rates and interest rates, the notion of variable rate firmly grounded as a variable relationship between the changes in two quantities is important for differentiation. The notion of rate expressing a measure of the relationship between changes in two quantities is significant, so quantification of rate is important. Finally, the applicability of rate to any context where a relationship exists between the changes in two quantities is also necessary. The critical aspects discussed in this section have been summarised in Figure 12.

ECA 1. Rate as a relationship between changes in two quantities

ECA 2. Rate as a relationship between changes in two quantities which may vary

ECA 3. Rate as a numerical relationship between changes in two quantities which may vary

ECA 4. Rate as a numerical relationship between changes in two quantities which may vary and is applicable to any context.

Figure 12: Educationally Critical Aspects of the Concept of Rate 
It is interesting to note there is a further conceptual gap between Category $\mathrm{H}$ conception and the 'instantaneous rate of change' met in calculus. Perhaps this is an additional educationally critical aspect to be addressed by the teachers of calculus. However, it is not listed in Figure 12 as it does not arise from the empirical evidence of this study. The next section discusses the implications of these ECA of rate for teachers' pedagogical content knowledge and the instructional sequence authors embed in their textbooks.

\section{Implications \& Conclusions}

The ECA of rate found in this study may provide a structure for the development of a conception of rate which coincides with elements of an expert's concept of rate as it is encapsulated in mathematical definitions. It is intended that these ECA offer assistance for the preparation of appropriate curriculum materials to particularly attend to these critical aspects. These ECAs might be used in revising curricula by changing the focus in a study of rate from rules to relationships.

Emphasising the relationship between the changes in two quantities when students first meet the notion of rate may facilitate rate being seen as a relationship and not a single value resulting from some calculation and so address ECA 1: Rate as a relationship between changes in two quantities.

Expressing the relationship, in descriptive words, between the variables in a variety of familiar rate contexts, including both constant and variable rate contexts would address ECA 2: Rate as a relationship between changes in two quantities which may vary.

Attending to quantification of rate during the teaching of linear functions and functions where the rate varies would address ECA 3: Rate as a numerical relationship between changes in two quantities which may vary. It may be beneficial for students' earliest exposure to functions to include functions where rate varies and for teaching to emphasise average rate. In this approach, linear functions and constant rate would be seen as special cases.

Studying rate in a variety of contexts, including contexts involving distance and time; other temporal rates; and rates that do not involve time as one of the variables would emphasise rate, independent of context and thus ECA 4: Rate as a numerical relationship between changes in two quantities which may vary and is applicable to any context.

In this way, teaching focused on the four Educationally Critical Aspects of Rate identified in this study will provide guidance for the development of students' mathematical concept of rate.

\section{Acknowledgement:}

An earlier version of this paper appeared in the conference proceedings of MERGA 2009: MERGA32 Wellington, NZ. The authors also wish to thank the editor and reviewers for their work that contributed to the quality of this paper.

\section{References}

Akerlind, G. (2005). Phenomenographic methods: A case illustration paradigm. In Bowden, J. A., \& Green, P. (Eds) Doing developmental phenomenography (pp. 103-127). Melbourne, Australia: RMIT University Press.

Akerlind, G., Bowden, J., \& Green, P. (2005). Learning to do phenomenography: A reflective discussion. In Bowden, J. A., \& Green, P. (Eds) Doing developmental phenomenography (pp. 74-100). Melbourne, Australia: RMIT University Press.

Asiala, M., Cottrill, J., Dubinsky, E., \& Schwingendorf, K. E. (1997). The development of students' graphical understanding of the derivative. Journal of Mathematical Behavior, 16(4), 399-431.

Bell, A., \& Onslow, B. (1987). Multiplicative structures: Development of the understanding of rates (intensive quantities). In J. Bergeron, N. Herscovics \& C. Kieran (Eds.), Proceedings of the 11th Conference of the International Group for the Psychology of Mathematics Education (Vol.1, pp. 275281). Montreal, Canada: PME.

Bezuidenhout, J. (1998). First-year university students' understanding of rate of change. International Journal of Mathematical Education in Science \& Technology, 29(3), 389-399.

Bingolbali, E. \& Monaghan, J. (2008). Concept image revisited. Educational Studies in

Mathematics, 68, $19-35$

Bowden, J. (1994). The nature of phenomenographic research. In J. Bowden \& E. Walsh (Eds.), Phenomenographic research: Variations in method. (pp. 43-55). Melbourne, Australia: RMIT Publications.

Cope, C. (2000). Educationally critical aspects of the experience of learning about the concept of an information system. Unpublished PhD thesis [On-line]. Accessed 29 January, 2010 from http://www.ironbark.bendigo.latrobe.edu.au/staff/cope/cope-thesis.pdf 
delos Santos, A. \& Thomas, M. (2003). Representational ability and understanding of derivative. In N.A.Pateman, B.J. Dougherty \& J.T. Zilliox (Eds.), Proceedings of the Psychology of Mathematics Education Annual Conference, (Vol 2 pp. 325-332) Honolulu, USA:PME.

Glazer, E., \& McDonnell, J. (2002). Real-life math: Everyday use of mathematical concepts.

London: Greedwood Press.

Herbert, S. \& Pierce, R. (2007). Video evidence: What gestures tell us about students'

understanding of rate of change. In, Watson, J. \& Beswick, K. (Eds). Mathematics: Essential Research, Essential Practice: Proceedings of the Annual Conference of the Mathematics Education Research Group of Australasia (pp. 162-371). Hobart, Australia: MERGA.

Kaput, J. (1992). Technology and mathematics education. In D.Grouws (Ed.), Handbook of research on mathematics teaching and learning (pp. 515-556). New York: Macmillan.

Kaput, J., \& Schorr, R. (2002). Changing representational infrastructures changes most everything: The case of SimCalc, algebra \& calculus. In K. Heid \& G. Blume (Eds.), Research on the impact of technology on the teaching and learning of mathematics (pp. 47-75). Mahwah, NJ: Erlbaum.

Lamon, S. (1999). Teaching fractions and ratios for understanding: Essential content knowledge and instructional strategies for teachers. London: Lawrence Erlbaum Assoc.

Lopez-Gay, R., Martinez-Torregrosa, J., Gras-Marti, A \& Torregrosa, G. (2002). On how to best introduce the concept of differential in physics. In Michelini, M. \& Cobal, M. (Eds.). Developing formal thinking in physics: First international Girep seminar (pp. 329-333). Udine, Italy: University of Udine.

Marton, F. (1988). Phenomenography: Exploring different conceptions of reality. In D. M.

Fetterman (Ed.), Qualitative approaches to evaluation in education: The silent scientific revolution. (pp.176-205) New York: Praeger.

Marton, F., \& Booth, S. (1997). Learning and awareness. Mahwah N.J. : L. Erlbaum Associates.

Marton, F., Runesson, U. \& Tsui, A. (2004). The space of learning. In Marton, F. \& Tsui, A.B.M.

(Eds) Classroom discourse and the space of learning. (pp. 3-42). Mahwak: Lawrence Erlbaum Assoc.

Oliveros, R., \& Santos-Trigo, M. (1997). Students' cognitive approaches to the concept of rate. In Dossey, John A., Swafford, Jane O., Parmantie, Marilyn, Dossey, Anne E., (Eds.). Proceedings of the Annual Conference of the North American Chapter of International Group for the Psychology of Mathematics Education (pp. 31-36). Bloomington-Normal, IL: NA-PME.

Orton, A. (1983). Students' understanding of differentiation. Educational Studies in Mathematics, $14,235-250$.

Piaget, J. (1970). The child's conception of movement and speed (G. Holloway \& M. Mackenzie, Trans.). London: Routledge \& K. Paul.

Rowland, D., \& Jovanoski, Z. (2004). Student interpretations of the terms in first-order ordinary differential equations in modelling contexts. International Journal of Mathematical Education in Science and Technology, 35(4), 503-516.

Smith, C., Maclin, D., Grosslight, L., \& Davis, H. (1997). Teaching for understanding: A study of students' preinstruction theories of matter and a comparison of the effectiveness of two approaches to teaching about matter and density. Cognition and Instruction, 15(3), 317-393.

Stewart, J. (2007). Essential calculus. Pacific Grove, CA: Brooks/Cole.

Stump, S. (2001). High school precalculus student's understanding of slope as measure. School Science \& Mathematics, 101(2), 81-89.

Tall, D. (1985). Understanding the calculus. Mathematics Teaching, 110, 49- 53.

Thompson, P. (1994). Images of rate and operational understanding of the fundamental theorem of calculus. Educational Studies in Mathematics, 26(2), 229-274.

Tourniaire, F., \& Pulos, S. (1985). Proportional reasoning: A review of the literature. Educational Studies in Mathematics, 16(2), 181-204.

Ubuz, B. (2001). First Year engineering students' learning of point of tangency, numerical calculations of gradients, and the approximate value of a function at a point through computers. Journal of Computers in Mathematics and Science Teaching. 20(1), 113-137.

Ubuz, B. (2007). Interpreting a graph and constructing its derivative graph: Stability and change in students' conceptions. International Journal of Mathematics Education in Science and Technology. 38(5), 609-637.

Victorian Curriculum \& Assessment Authority (VCAA). (2007). Victorian Essential Learning Standards: Mathematics. Retrieved May 31, 2007, from http://vels.vcaa.vic.edu.au/essential/discipline/mathematics/

Zandieh, M. (2000). A theoretical framework for analyzing student understanding of the concept of derivative. In E. Dubinsky, J. Kaput \& A. H. Schoenfeld (Eds.), Research in collegiate mathematics education (pp. 103-127). Providence, RI: American Mathematical Society. 
